\title{
Mateja Veble
}

\section{Televizijski šport}

Ključne besede: televizija, šport, mediatizacija športa, nogomet, oddajanje, komentar

Zakaj je formula 1 popularnejša od plavanja, zakaj o akrobatskem smučanju ne vemo toliko kot o alpskem, zakaj povprečen človek ne ve dosti o kriketu in se snooker glede svoje popularnosti ne more primerjati $\mathrm{z}$ nogometom? Ali je $\mathrm{z}$ omenjenimi športnimi zvrstmi kaj narobe? Odgovor je ne. Ti športi so povsem enako dinamični, aktivni in privlačni. Dejstvo pa je, da jih redkokdaj zasledimo na televiziji, kar je v današnjem času enako, kot da jih ne bi bilo.

Mediji imajo na šport velik vpliv. Pri tem je največjo vlogo do sedaj zagotovo odigrala televizija. Ker je medij posrednik med športniki in gledalci, lahko v želji, da bi bil gledalec zadovoljen, športne panoge spreminja po svojih zahtevah, oziroma ker se $\mathrm{z}$ mediatizacijo krepi vloga gledalca, prihaja marsikje do prilagoditev oziroma sprememb poteka športnega dogodka.

Ko govorimo o razvoju medijske tehnologije in pomenu vstopa televizije v svet športnih dogodkov, so naša vprašanja fokusirana na problem spreminjanja športnega dogodka in kulturnega pomena športa v družbi. Šport se pogosto označuje kot zabava, kot nov opij za množice. Televizija je za šport postala osrednjega pomena. Veliki športni dogodki privabljajo trume televizijskih gledalcev. Postala pa je tudi pomemben vir dohodka za različne športne panoge ter je hkrati odprla vrata veliko večjim zaslužkom v obliki športnega sponzoriranja.

Že okrog leta 1960 je postalo povsem jasno, da je vloga televizije pri konstruiranju športnega dogodka tolikšna, da je šport primoran upoštevati njen vpliv pri oblikovanju svojih športnih dogodkov. Za televizijo je pomembno, da ima šport enostavna pravila, da se ga zlahka razume ter da je vizualen. To pomeni, da ga je mogoče predvajati brez večjih popravkov in raztegnitve same narave športnega dogodka. Poleg tega mora biti dogodek sposoben pritegniti sorazmerno veliko število gledalcev na sam kraj dogodka. Do leta 1970 so televizijski strokovnjaki športnemu svetu že postregli s svojimi zahtevami glede narave športnega dogodka, natančneje, leta 1979 sta Tony Preston in Tony McCarthy zasnovala pet osnovnih kriterijev, ki jim je moral zadostiti televizijski šport za takratno britansko televizijo ITV (Whannel, 1992, 78-79). Pravila, 
ki sta jih zapisala, so narekovala, da se šport ne sme dogajati na prevelikem prostoru, ker bi bilo s tem oteženo televizijsko snemanje. Prostor mora omogočati celovit in enovit pogled nanj. Pravila športne panoge morajo biti jasna in preprosta, da ljudje z lahkoto spremljajo in razumejo, kaj se dogaja na terenu. Športna disciplina se mora končati v doglednem, za medij sprejemljivem času in mora zanimati ljudi do te mere, da bodo pripravljeni slediti dogodku pred zasloni. Vsak predvajan športni dogodek mora nujno vsebovati komponente človekovih sposobnosti, pri tem pa je nujna tekmovalnost na podlagi objektivne merljivosti. Poleg omenjenih kriterijev iz leta 1979 obstajata vsaj še dva za današnji televizijski šport nujna pogoja, ki omogočata identifikacijo s športom. To sta dramatizacija in narativizacija. Šport velikokrat ponuja mejni užitek med negotovostjo in zanesljivostjo. Najlepše pri vsem je zagotovo nepoznavanje razpleta celotnega dogodka. Nepredvidljivost športnega dogodka je zakoreninjena $\mathrm{v}$ samo naravo športa, vendar pa mora šport kot oblika zabave ponujati tudi določeno obliko gotovosti. Četudi je izid poteka dogodka vedno nepredvidljiv in negotov, je sama oblika toliko bolj predvidljiva, saj zagotavlja, da bo pri spremljanju za zabavo vedno poskrbljeno.

Danes poznamo več oblik podajanja televizijskega športa. V grobem jih lahko razdelimo v dve osnovni skupini; na neposredno prenašanje športnih dogodkov ter na različne vrste predvajanja posnetkov in športnih reportaž. Pri obeh skupinah je treba nujno upoštevati zahtevo po zanimivosti vsakega trenutka spremljanja oddaje oziroma prenosa ter njeno vizualno pripovednost, ki vključuje začetek, sredino, konec in dramatičnost videnega (Whannel, 1992). Čeprav ob omembi TV športa največkrat pomislimo na športne prenose, ne gre povsem zanemariti drugih oblik predvajanja športnih dogodkov. Garry Whannel ${ }^{1} \mathrm{v}$ omenjeno skupino prišteva reportažo, ki po svoji definiciji zajema časovno zamaknjeno in nekoliko manj zanimivo obliko predvajanja športa na televiziji, posnetke tekmovanj, pri čemer gre za skrajšane posnetke, namenjene gledalcem, ki si niso mogli prenosa ogledati v živo in si ga v skrajšani obliki lahko ogledajo pozneje, ter vrhunce (highlights), kjer gre za oddaje, ki nimajo namena realno prikazovati športnih dogodkov. Njihov namen je poudariti določene značilnosti športne panoge, jo pokazati na čim bolj zanimiv način. Govorimo o osvetlitvah najpomembnejših dogodkov na tekmovanju s poudarkom na akciji, dramatizaciji in zvezdah tekmovanja. Tovrstna koncentrirana oblika športnih dogodkov ni informativnega značaja. $\mathrm{V}$ želji po prikazovanju vizualno zanimivejše oblike se televizijske ekipe poslužujejo vrste vizualnih učinkov, kot so na primer zamrznitev slike, posnetki iz nenavadnih zornih kotov ipd. Gre za spektakularizacijo športa, ki se kaže v izboru najzanimivejših in najpomembnejših trenutkov nekega športnega dogodka. Reportažni in dokumentarni posnetki so pogosto sestavljeni tako,

1 Garry Whannel je temeljni avtor na področju študij športa in medijev. 
da je šport na zaslonu videti precej bolj dinamičen in krajši, kar ga dela zanimivejšega za gledalca (Whannel, 1992).

Neposredni televizijski prenos lahko opredelimo kot televizijsko oddajanje, ki ga na zaslonu spremljamo sočasno s potekom dogajanja. Imenujemo ga »živi« prenos ali prenos oziroma oddaja »v živo«. Predhodni uspeh radijskih športnih prenosov in splošno sprejeto prepričanje, da je televizija nadgradila radijske zmožnosti, sta pospešila razvoj televizijskega prenašanja športnih dogodkov. Pripomoglo je tudi dejstvo, da so s televizijskimi prenosi, tako v ZDA kot v Veliki Britaniji, upravljale tiste organizacije, ki so se prej že »dokazale« $\mathrm{z}$ radijskimi prenosi. Prvi televizijski športni prenos v ZDA se je zgodil 17. maja 1939. Komercialna radiodifuzna televizijska mreža NBC je $\mathrm{z}$ eno samo kamero prenašala baseballsko tekmo med univerzama Princeton in Columbia. Prvi prenos ni navdušil ne gledalcev ne novinarjev. Kritike so letele predvsem na pomanjkljivost tehnološke opreme. Na vrhu tribune za gledalce je bila postavljena kamera, ki ni bila ustrezna za pokrivanje tekem na tako velikem terenu, kot sta baseballsko ali nogometno igrišče. Kar zadeva športne prenose v Evropi, se ti najprej uveljavijo v Veliki Britaniji. Televizijska postaja BBC je športni dogodek prvič, eksperimentalno, prenašala 21. junija 1937. Šlo je za kratek 25-minutni prenos moškega teniškega dvoboja iz Wimbledona. Od takrat je BBC redno prenašala tekme kriketa, leta 1939 pa prvič pokal angleške nogometne zveze, t. i. FA Cup (Goldlust, 1987, 78). Tehnične in programske spremembe so nastopile šele po drugi svetovni vojni, ko so se znanstveniki ponovno začeli ukvarjati z izboljšavo kamer, oddajnikov in televizijskih sprejemnikov. Ko je leta 1962 prišlo do satelitske povezave med ZDA in Evropo, je športne dogodke začel spremljati ves svet. Začetni televizijski prenosi so bili narejeni v črno-beli tehniki, šele po letu 1950 so gledalci lahko filme, oddaje in s tem tudi športne spektakle spremljali v barvah. Poplava kamer in mikrofonov, pritrjenih nanje ter dodatno razpostavljenih ob igrišču na tekmah najvišjega kakovostnega razreda, se je začela na svetovnem nogometnem prvenstvu leta 1994 v ZDA. S spremembo tehnologije se je vseskozi spreminjala tudi programska shema, šport je postajal vse bolj pomemben del programa vsake televizije. Če se vprašamo o vrednosti športnega prenosa kot takega, lahko zatrdimo, da je njegova vrednost tolikšna, da nam kot televizijskim gledalcem včerajšnja tekma danes ni več pomembna. Whannel (1992) ugotavlja, da gre, čeprav televizija zatrjuje, da je njena naloga slikanje realnosti, v resnici za veliko več kot zgolj to. Televizija namreč konstruira eno izmed možnih realnosti, in to s pozicije pogleda idealnega gledalca. Obstaja nešteto form, stilov in estetskih določil za ponazoritev realnosti, ki se jih televizija poslužuje pri športnih prenosih.

Televizijski prenos športnega dogodka je strukturno razpet med tri plasti dogodkovnosti, ki se odvijajo sočasno: tekmovalni (igralni) dogodek (game event), 
dogajanje na prizorišču (stadium event) ter medijski dogodek (medium event) (Goldlust, 1987, 85). Medijski dogodek, katerega del je tudi sam prenos tekme (coverage of the game), Goldlust definira kot celotno televizijsko oddajanje (total telecast). Televizijski čas simultano povzema realni čas. Medijski dogodek zajema tekmovalni dogodek in dogajanje ob njem, vse to pa je dopolnjeno s komentarji, intervjuji, grafičnimi vložki in dizajnnom, pa tudi z reklamnim materialom sponzorjev in propagiranjem lastne televizijske postaje. Med prvimi, ki televiziji priznavajo določeno »umetniško držo« in »estetsko potencialnost«, je zagotovo Umberto Eco (glej Vidmar Horvat, 1993). Eco fenomen televizijske produkcije kot potencialno estetske produkcije opre na specifično televizijsko strukturo neposrednega prenosa. Ta po avtorjevem ${ }^{2}$ mnenju v toku svoje realizacije preide tri stopnje »umetniške operacije«: izbor, kompozicijo in interpretacijo. Faze, ki se dogajajo simultano, so po Ecovem mnenju del režiserjeve zgodbe: montaža (izbor slik, ki ga zagotavljajo različno postavljene kamere) postane že hkrati režiserjeva interpretacija dogodka, logična postavitev prvotno kronoloških faz dogajanja. Od trenutka, ko dogodek steče, dobiva režiser na treh zaslonih slike telekamer, s katerimi operaterji po njegovem naročilu izberejo kadre v mejah svojega vidnega polja. Eco meni, da gre pri tem za uporabo določenega števila objektivov, ki omogočajo, da se vidno polje omeji ali razširi ter da se poudari globina. Po njegovem mnenju je režiser postavljen pred nešteto izbir, dogodek si more izmisliti v trenutku, ko se ta zares odvija. Od začetka dobiva sliko na treh zaslonih, med katerimi mora izbrati le eno od njih. Njegov izbor tako postane kompozicija, naracija, diskurzivna izenačitev slik, analitično izoliranih v kontekstu obsežnega niza dogodkov, ki se odvijajo hkrati in počez. Neposredni prenos je vselej režiserjeva pripoved o tem dogodku, njegova lastna interpretacija. Pripovedovalec je vselej že del pripovedi. Dober prenos se naredi $\mathrm{Z}$ aktualizacijo določenega tipa režije, dramaturgije in komentarja. Vidmarjeva (1993) meni, da gre za pravo umetniško držo, ki je neodvisna od »dodatne« interpretacije »studijskega « komentatorja. Vloga režiserja je redukcionizmu matematičnega razmerja podvržena do te mere, da mora, če želi prikazati umetnost določene športne panoge, najprej pokazati odsotnost svoje lastne vmesnosti. »Takoj ko ne vidimo več pogleda posrednika, prenosnika, »režiserja«, smo že pripravljeni za potovanje po deželah, ki nam jih predstavlja televizija, in kjer televizija v resnici začne predstavljati samo sebe« (Vidmar Horvat, 1993).

Ko govorimo o vizualnih ravneh televizijskega športa, sta potreba po prikazovanju resničnega dogodka in želja po izgradnji zabavnega trenutka videti kot dva nasprotujoča si momenta. Obe formi zasledimo v vseh oblikah športa. Forma realizma organizira vizualne slike tako, da omogočijo transparentnost dogodka, ki se odvija pred našimi očmi. Davis (v Whannel, 1992, 32) zapiše tole pravilo: »Potegnite namišljeno črto od

2 Razmišljanja in trditve Umberta Eca so v celoti povzeti po članku Ksenije Vidmar Horvat (1993). 
sredine nogometnega igrišča od gola do gola in držite kamere na eni strani. Ni važno, kako blizu linije pridete, ne smete je preiti. V trenutku, ko bi do tega prišlo, bi namreč občinstvo povsem izgubilo občutek za prostorsko orientacijo.« Medtem forma zabave organizira svoje vizualne podobe iz potrebe po izpostavitvi momentov, ki ponujajo užitek in pridobijo pozornost gledalcev - akcije, zvezdniki in drame na zelenici (Whannel, 1992, 94). Da bi bila reprezentacija igre kar se da podobna originalu, se je televizija vse od svojih začetkov posluževala konvencionalnih metod filmskega realističnega predvajanja (Sandvoss, 1992). Ob tem je prevzela pravilo snemanja pod kotom 180 stopinj, ${ }^{3}$ pravilo komplementarnih kotov ipd. Omenjene konvencije so posledica težnje po kazanju resničnega dogodka, ki je nepristranski. Pri televizijskih športnih prenosih poleg načela realizma zasledimo tudi načelo iluzionizma. Zaradi fizične odsotnosti in oddaljenosti je treba proizvesti estetske in ideološke učinke, ki jih gledalec lahko prepozna kot luksuz in s tem zadovolji svoj prvotni manko. Garry Whannel v knjigi Fields of vision (1992, 96-101) opredeli šest tipov vizualne transformacije športnih prenosov. Položaj, ki ga režiserji najpogosteje uporabljajo za generalni pogled na akcijo, se imenuje "prime camera« ali "prime position«. Večina drugih posnetkov je do "prime position« v podrejenem odnosu. Pri nogometu ${ }^{4}$ na primer je ta pozicija ena sama. Za omenjeni položaj kamere bi lahko rekli, da je enak pogledu idealnega gledalca s perfektnim glediščem. Kot prvega Whannel navaja preprosti tip, kjer se športna akcija $s$ "prime position " pokriva $\mathrm{z}$ rezi, splošnimi in srednjimi plani (long shots in medium shots), bližnji plani (close ups) pa so rezervirani za trenutke pred in po akciji. Pri cutway gre za specifično obliko natančnih kratkih rezov, ki ob prekinitvah pospešijo dogajanje (omenjeni tip transformacije je značilen za športe, kot sta boks in tenis). Kot tretje izpostavimo vzorce rezov, kjer gre kljub osnovni prime position za integralno uporabo kamer. Poglejmo na primeru nogometa. Plani se bodo premikali od splošnega do srednjega, v trenutku ko se akcija na igrišču ustavi, pa nemudoma preklopijo na bližnjega. Nekoliko drugače je s športi, ki jih televizija pokriva s kamerami na način prostorske mobilnosti, pri njih začenja prime position izgubljati na pomenu. Eden izmed športov, pri katerem prihaja do enakovrednih pogledov, je na primer atletika. Kot zadnji tip vizualne transformacije, značilne za športe, ki se odvijajo na večjih območjih, na primer formula 1, štejemo prostorsko fragmentacijo. Pri omenjenem tipu je težko govoriti o prime position, razen v ciljnih predelih, dogajanje se namreč pokriva s splošnimi plani. Whannel (1992) opozarja na dualnosti, ki so prisotne na vizualni ravni slehernega televizijskega športa. Športni dogodek sam po

3 Zaradi pojava novih tehnoloških sredstev televizijske reprezentacije, od zoom objektivov do videorekorderjev in računalniških animacij, je televizijski nogomet postal hiperrealen. V zadnjih nekaj letih so bili, denimo, uvedeni obratni posnetki akcij, s čimer je bilo prekršeno pravilo 180 stopinj kot glavno pravilo realističnega podajanja igre (Sandvoss, 2003, 149).

$4 \mathrm{~V}$ članku navajam primere iz prenosov televizijskega nogometa. Z omenjenim področjem sem se podrobneje ukvarjala v svojem diplomskem delu. 
sebi predstavlja neobdelano gradivo, ki ga televizija s konstrukcijo specifičnega teksta pretvarja v popolnoma drugačno tvorbo. Športni prenos, ki je televizijski in medijski spektakel, je torej strukturiran produkt. Proces njegove konstrukcije je determiniran z realnostjo dogodka. Gre za mešanje dveh tokov, pri čemer športni dogodek s svojo naravo predstavlja meje možnostim različnih medijskih reprezentacij, TV medij pa s kodi televizijskih reprezentacij in tehničnimi zmogljivostmi vpliva na podobo tekme. Forma realizma, kjer gre za prikaz resničnega dogodka, tj. za formo »v živo«, se nenehoma dopolnjuje s formo zabave, kjer igrajo bližnji plani neprecenljivo vlogo pri konstrukciji športa, kot ga poznamo danes. Kriterij, kako zadostiti maksimumu akcije ob minimumu prostora, predstavlja ideal, ki mu poskuša režiser vedno znova optimalno zadostiti z uporabo srednjih in bližnjih planov ter $\mathrm{z}$ rezanjem dogajanja. Medtem ko je prostor manipuliran s položaji kamer in vzorcem rezanja, je čas pri nogometu manipuliran s strukturami ponovitev ali ustavitev: ponavljanje akcij (action replay), počasni (slow replays, slow motion) in zaustavljeni posnetki (freeze-framing replays, stop action), zbrani vrhunci (edited highlights) ter s časom za dramatizacijo akcije: hitri rezi (instant replays, cuttings). Čas se s tem intenzivira in objektivno subjektivira. Ekranizacija (framing) je tista, ki proizvede prisotnost in odsotnost. Režiser nekaj pokaže, hkrati pa s tem nekaj drugega ignorira.

Razvoj nove tehnologije, npr. videoposnetkov, slow motion replayev, računalniško obdelanih tabel rezultatov, statistik ipd., je omogočil povečano zmožnost vključevanja materiala iz drugih virov zunaj neposrednega prizorišča, kar je izoblikovalo model medijskega dogodka na način, ki je v precejšnji meri določen s prizadevanji za »dobro televizijo« (Kotnik, 2001). Pri televizijskih športnih prenosih so v ospredju njegove vizualne komponente, med katere prištevamo vnaprej pripravljeno gradivo (Goldlust, 1987): v večini primerov gre za vnaprej posnete intervjuje, arhivske posnetke ali drugo stransko gradivo, inkorporirano $\mathrm{v}$ »živi« prenos. Na televiziji tako rekoč prevladuje uporaba grafik. Te so lahko sprotno ali predhodno proizvedene. Na zaslonih se nenehno pojavljajo besede, ki identificirajo program, televizijsko hišo ter športne korporacije in pokrovitelje, odgovorne za izvedbo športnega dogodka. Naslove, napise, imena tekmovalcev, statistiko rezultatov ipd. prištevamo med predhodno pripravljene grafike. Če vzamemo primer iz nogometa, sledi pred začetkom vsake tekme prikaz igralne postavitve obeh ekip. Povečini gre za imenski prikaz, ki pa je lahko obogaten tudi s slikovnim gradivom, kar pomeni, da je imenu dodana še slika igralca. Medtem sprotno proizvedena grafika zajema tekoči čas, trenutni rezultat, pojasnjevalne diagrame in analize posameznih akcij. Ker je športni dogodek časovno omejen, sta prikaz tekočega časa in trenutnega rezultata nepogrešljiva elementa prenosa »v živo«. Že utečena praksa je, da po končani tekmi sledi analiza v studiu. Ker se povprečen gledalec ne spozna na sloge igranja in tehnično izvedbo akcij, so računalniško proizvedene grafike, ki se jih 
studijski komentatorji poslužujejo za pojasnjevanje igre, več kot priročne, da gledalcu približajo ter pojasnijo gibanje in podaje na igrišču. Vso športno aktivnost $\mathrm{v}$ sliki, $\mathrm{z}$ vsemi njenimi prekinitvami (medicinska oskrba igralca na igrišču) in TV spektaklom pred in po tekmi, prištevamo $\mathrm{k}$ poteku tekme, tj. $\mathrm{k}$ njenim vizualnim komponentam. Nekateri športi, med katere sodi tudi nogomet, potekajo z dokaj malo prekinitvami in tako ohranjajo kontinuiteto poteka igre. Uporaba videoposnetkov je športne prenose obogatila s časovno neomejenostjo. Ker je športni dogodek mogoče posneti, ga ni nujno predvajati v »realnem času«, lahko ga predvajamo v času, ki obljublja večjo gledanost. Najpomembnejšo vizualno komponento zagotovo predstavljajo počasni posnetki razburljivih in odločilnih delov športne akcije. Gre za posnetke, ki so sami sebi namen in pojasnjujejo sami sebe. Vstavljeni so na mestih, kjer je potek športne akcije ustavljen, kar še poveličuje njihovo kredibilnost. Če upoštevamo, da je dogajanje $\mathrm{v}$ večini športov razmeroma hitro, gledalec na tribuni pogosto nima dobrega pogleda na ključne trenutke napada ali konflikta. Tehnične izboljšave so omogočile jasnost pogleda ter $s$ tem gledalcem zagotovile možnost podrobnejše analize in presoje posamezne akcije. Gledalec »bolje vidi«, česar »realno« ni dobro videl. Televizijskemu občinstvu je podarjeno privilegirano kognitivno in estetsko izkustvo športnega tekmovanja, ki je povsem drugačno od izkustva na samem kraju športnega dogodka. Posnetek je mogoče ustaviti in zamrzniti na vsaki točki. Negibna slika včasih ponuja številne možnosti za dobro interpretacijo ali oceno situacije. Momenti se potrdijo kot odločilni in dramatični. Pogosto se za pojasnitev situacije uporabljajo tudi posnetki kamer, ki jih režiser ne uporabi pri prenosu tekme. Kot že omenjeno spontan ali vnaprej pripravljen prenos netekmovalnih elementov dogajanja (tako na/ob igrišču kot na stadionu) prav tako prištevamo $\mathrm{k}$ vizualnim komponentam. Tu imamo največkrat $\mathrm{v}$ mislih posnetke občinstva, ki se odziva na dogajanje na terenu. Kamere se ustavijo na navijačih, sotekmovalcih in trenerjih, da bi prikazale njihove reakcije v ključnih trenutkih posameznih akcij. Predvsem posnetki trenerjev v odločilnih trenutkih so nepogrešljiv del prenosa tekmovanja. Nekaj besed je treba nameniti tudi reklamam, ki so del prenosa športnih dogodkov in so vezni člen med televizijo, sponzorji in gledalci. Najpogosteje so predvajane tiste, katerih sponzorji so glavni pokrovitelji dogodka. V primeru športne zvrsti, za katero je značilna kontinuiteta poteka igre, kot recimo pri nogometu, so reklame vstavljene v času daljših prekinitev tekme. Najpogosteje gre za čas prekinitve ob polčasu. Namen intenzivne propagande, katere del so reklame, ${ }^{5}$ je še pred začetkom tekmovanja pri ljudeh spodbuditi željo po gledanju spektakla, ki ga ponuja televizija.

Pod avditivne komponente športnega prenosa tako štejemo naslednje registre (Goldlust, 1987, 91-93): 1. tonske zvočne zapise vnaprej pripravljenega gradiva, med

5 Primer uradnega napovednika FIFA WORLD CUP 2010, dostopno na http://www.youtube.com/ watch? $=$ dBZtHAVvslQ [16. 2. 2012]. 
katere uvrščamo reklame, predhodno posnete intervjuje, prispevke ipd.; 2. glasbo, ki jo lahko uporabimo kot podlago najavne in odjavne špice prenosov ali kot ozadje predhodno pripravljenih prispevkov; 3. »mednarodni zvok« je termin, ki ga televizija uporablja za »naravni« zvok, ki nastaja na samem kraju prizorišča dogajanja. S postavitvijo številnih mikrofonov okoli igrišča, $v$ nekaterih primerih tudi na samo igrišče, se zagotovi tonski zapis, ki »avtentizira okoliščine prenosa« (Kotnik, 2001). Gledalcem pred domačimi TV sprejemniki se poustvarja dogajanje na stadionu, s čimer se zmanjšuje občutek fizične oddaljenosti in zapostavljenosti, povečujejo pa se njihove možnosti za vživetje v medijski dogodek. Najpomembnejši delež zvočnega zapisa je dodeljen športnim komentatorjem oziroma celotni komentatorski ekipi. Pri tem je zanimivo, da je kljub temu, da lahko športne prenose gledamo tudi brez zvoka, ${ }^{6}$ $\mathrm{v}$ študijah o televizijskem športu veliko besed namenjenih prav vlogi komentatorja. Ker je velik del atmosfere televizijskega športa grajen prav prek zvoka, se bom v nadaljevanju nekoliko bolj poglobila $\mathrm{v}$ zadnja dva registra. $\mathrm{V}$ televizijskem športu najdemo veliko izvorov zvoka. Lep primer, kako je televizija napredovala pri prenosih nogometnih tekem, je videoposnetek tekme med Brazilijo in Anglijo iz leta 1970. ${ }^{7}$

Po mnenju Kennedyja in Hillsa (2009) je ena največjih sprememb zagotovo kakovost zvoka. Posnetek, ki ga navajata kot primer, je namreč dokaj nerazumljiv. Glas komentatorja se pojavlja nekje iz ozadja, kar daje občutek, da je oddaljen od dogajanja na zelenici. Medtem je mogoče slišati nenehen hrup množice, skupaj z ambientalnimi zvoki, ki jih ujame mikrofon, npr. šum vetra. Ob poslušanju tovrstnih posnetkov se nam zgolj dodatno potrdi prepričanje o pomenu kakovosti zvoka pri prenosu športnih dogodkov in kako je razvoj tehnologije omogočil izboljšanje kakovosti zvoka.

Koncept komentarja je eden osnovnih prijemov mediatizacije športnega dogodka (Barnett, 1990). Sega še v čase radijskega predvajanja, in ko se kasneje prenese na televizijo, kljub temu da je $\mathrm{z}$ razvojem tehnologije optika očitno prevladala nad zvokom, ohrani dominantno pozicijo. Namesto da bi bil gledalcu zagotovljen neposreden dostop do dogodka prek vizualne podobe tekme, združene $\mathrm{z}$ mednarodnim zvokom, ostaja komentator tisti, ki poskuša postaviti in povezati razlago slike $\mathrm{z}$ analizo (dogajanja), vrednotenjem rezultatov in oceno tekmovanja. Komentator opisuje, razlaga, analizira in napoveduje dogajanje ter povečuje dramatičnost, ki je tekmi v določenem trenutku morda primanjkuje. Ob vsem tem poskuša uvrstiti prostor posamezne tekme $\mathrm{v}$ širši kontekst zgodovinsko-razvojnega okvira tekmovanja. V 50. letih so bili britanski športni producenti zaskrbljeni glede priljubljenosti televizijskega športa. Treba je bilo najti način, kako se razširiti od poznavalcev športa do manj privrženih množic

6 Če spremljamo tekmo na javnem mestu, je komentarje zaradi hrupa iz okolja pogosto nemogoče slišati.

7 Dostopno na http://www.youtube.com/watch?v=Zs2n27JBMSs\&feature=related [16. 2. 2012]. 
gledalcev, ki dnevno posedajo pred TV zasloni. Konvencije, sprejete v tem obdobju, ki so ostale pri televizijskem športu vse do današnjega dne, so bile namenjene poživitvi oddajanja in ugoditvi nenehnemu vključevanju občinstva novincev oziroma občasnih gledalcev $\mathrm{v}$ svet športa. Za dober televizijski športni komentar veljajo naslednja določila (Whannel, 1992): preprostost in spontanost, obdržati zanimanje gledalcev $z$ negotovostjo, pojasnjevanje in interpretacija, oblikovanje podatkov v logični red ter naj glas množice govori zase. Leta 1966 Brian Johnson (glej Whannel, 1992, 28) zapiše tri dodatna "zlata pravila «, ki komentatorju velevajo: naj ne govori, česar ne more dodati $k$ sliki, naj ne opisuje, kar zaslon vidi, ter naj kameri dovoli, da pove svojo zgodbo. Ali šestinštirideset let pozneje komentatorji sledijo »zlatim pravilom«, naj presodi vsak sam. Bistvo komentarja je v njegovem opisnem, vrednostnem in dramatičnem elementu (Goldlust, 1987, 92-96). Opisni element je sestavljen iz opisnih ocen in pripovedi o poteku akcije. Poleg žargona, ki se ga poslužujejo komentatorji za opis veščin, taktik in slogov, so pripovedi polne zgodb, ki se nanašajo na zgodovino uspehov posameznih športnih akterjev. Vrednostni element je inkorporiran v opisno komponento, ki pojasnjuje smiselnost tekmovanja, napoveduje razvoj dogodkov itd. Pogosta praksa je pojasnjevanje statistik, diagramov in drugih grafičnih tabel, ki se v času dogodka prikazujejo na zaslonu. Najpogosteje gre za statistične podatke o posameznih napakah ekip, času posedovanja žoge, številu strelov iz kota ipd. ${ }^{8} \mathrm{Te}$ metode so posledica modernističnega pogleda na šport, ki neguje konkurenčnost $\mathrm{v}$ športu. Pod vrednostni element prištevamo tako komentatorjeve ocene predhodnih nastopov moštev kot vpliv zunanjih tekmovalnih okoliščin. Komentatorji nam prav tako pojasnijo, kako vremenske okoliščine in tip igralne površine vplivajo na strategijo $\mathrm{v}$ posamezni igri. Televizija s prikazovanjem posnetkov od blizu komentatorjem omogoča, če ne skoraj zapoveduje, da se (in zanimivo je videti, kako radi to počnejo) poglabljajo tudi v psihologijo obrazov športnikov in svobodno interpretirajo pomen tistega, kar (oni) vidijo $\mathrm{v}$ »okviru kulturno standardiziranega vulgarnega modela motivacijske psihologije« (Kotnik, 2001).

Edina stvar, ki je kamere ne morejo narediti, je pričarati dramo tam, kjer je ni. Če je tekma dolgočasna, še tako sofisticirano delo kamer ne more poustvariti dramatičnosti (Barnett, 1990). Tu se kaže pomembnost komentatorja, katerega naloga je, da najde in izpostavi trenutke, s katerimi obdrži zanimanje gledalcev pred televizijskimi zasloni. Težava, na katero največkrat naletimo, je, kako sestaviti dober komentar, ki bo odražal pravo razmerje strokovnosti in popularnosti. Pogosto se zgodi, da je komentator televizijski človek, ki sicer svoje delo dobro opravlja, ne obvlada pa strokovne plati. Komentator verbalno podvaja sliko in podatke na njej. Nujno je, da je v tem bolj energičen od same slike. Temelj dinamičnega elementa so binarna nasprotja, ki jih

8 Primer igre $\mathrm{z}$ žogo, kot je nogomet. 
najdemo v vseh oblikah tekmovanj. Kot zapiše že Goldlust (1987, 94), so najpogosteje zastopane dvojice, ki se jih poslužujejo komentatorji za primerjanje posameznikov in ekip: moč/spretnost, favoriti/outsiderji; mladost (zanos, vitalnost)/starost (izkušenost, mojstrstvo); naravna sposobnost/trdovratna odločnost; temperament, ognjevitost/ hladnost, racionalnost; inovativnost, nepredvidljivost/mehanska disciplina, togost; prijateljstvo, naklonjenost/sovraštvo, tradicionalno rivalstvo. Neizrazit komentar je povsem odvečen. Če pa je diskurz kakovosten, lahko gledalec dobi veliko zanimivih informacij, ki mu pomagajo razumeti dogajanje na igrišču.

Televizija je temeljno preoblikovala načine, kako gledalci vidijo in izkusijo šport. Veliko teh sprememb lahko povzamemo kot racionalizacijo pogleda (Sandvoss, 2003). Televizijski šport je racionaliziral spremljanje športnega dogodka tako, da je dal prednost pogledu pred drugimi oblikami percepcije, kot sta npr. zvok (ki ga televizija povsem rekonstruira) ter odsotnost dimenzije vonja in fizičnega stika. Gledalci tako ne zaužijejo igre, ampak sliko igre. Televizijski šport proizvaja polje enakosti. Virillio (1991, v Sandvoss, 2003, 145) poudarja, da je glavna razlika med ogledom tekme v živo in prek televizije $\mathrm{v}$ tem, da na stadionu ni dveh posameznikov, ki bi videla igro enako, ker vsak obiskovalec zaseda točno določeno mesto, medtem ko je igra na zaslonu odsev tega, kar je videla kamera. Televizijski šport omogoča večjo zmožnost pregleda nad igro. Televizija želi kar najbolj učinkovito izrabiti pogled na omejen prostor, ki ga zagotavlja v svojih posnetkih. Namesto posnetkov celotnega igrišča, katerega deli so prazni ali zgolj posredno pomembni oziroma povezani s trenutnim dogajanjem $\mathrm{v}$ igri, je televizijski izbor posnetkov zasnovan tako, da je ključnega pomena za samo spremljanje tekme. Tako kot vsi racionalizirani sistemi produkcije televizija svojim uporabnikom ponuja smiseln pristop k športni igri, osredotočen na samo srčiko igre. Medtem ko nekateri trdijo, da gledanje televizije ne more nadomestiti veselja, ki ga v človeku ustvari spremljanje dogodka v živo, Morris in Nydahl (1985, v Whannel, 1992, 98) poudarjata, da lahko televizijski producenti vse od leta 1980 ustvarijo spektakle, ki s svojimi vizualnimi presenečenji ustvarjajo povsem drugačno polje dramatičnosti dogodka. S sposobnostjo hitre menjave med pogledi na igro je televizija izumila unikatno obliko drame. Na splošno počasni posnetki ponujajo povsem nove dogodke, izvzete iz realnega časa in prostora. Ne samo da spreminjajo našo percepcijo dogodka, ki ga gledamo, temveč tudi vzpostavljajo naša pričakovanja. Televizija je tako ustvarila spremembe v pričakovanjih občinstva in nove vrste frustracij, ki so vezane na željo po takojšnjem videnju ponovitev. Velikemu številu navijačev, tudi tistih, ki se udeležujejo tekem na stadionih, je televizijski posnetek, prej kot dejanski dogodek na igrišču, referenca definiranja realnosti igre. Veliko privržencev nogometa poudarja pomembno vlogo televizije pri spremljanju in razumevanju igre: »Med spremljanjem igre na stadionu dostikrat pomislim, kako rad bi videl ponovitev akcije, ki se je pravkar 
zgodila na igrišču « (Sandvoss, 2003, 148). Zgolj v času televizije so ljudje na stadionih začeli pogrešati posnetke ponovitev. $\mathrm{V}$ želji, da bi se čim bolj približali »hiperrealni simulaciji nogometne igre« (Sandvoss, 2003, 149) (pri nekaterih športih tudi zaradi oglasnih blokov), so klubi na svojih stadionih postavili ogromne videopanoje, ki gledalcu zagotavljajo enako časovno in perspektivno drobljenje slike, ki so ga navajeni iz televizijskih prenosov.

Ker je televizijski šport individualno videnje igre v kolektivnem okolju zamenjal $s$ kolektivnim videnjem igre $\mathrm{v}$ individualnem okolju, bi pričakovali, da se je ustvaril prepad in da prihodnost televizijskega športa leži $\mathrm{v}$ prenosih $\mathrm{s}$ praznih prizorišč. Resnica pa je prav nasprotna. Televizija je tista, ki legitimira, posveti dogodek za vreden ogleda. Ker gredo navijači na dogodek toliko rajši, kolikor bolj zanesljivo je, da bo ta na TV, lahko torej zatrdimo, da danes tudi realen šport izkušamo posredovano prek medija reprezentacije.

\section{Literatura}

Barnett, S., Games and sets, the changing face of sport on television, London 1990.

Goldlust, J., Playing for keeps; sport, the media and society, Melbourne 1987.

Kennedy, E. in drugi, Sport, media and society, Oxford, New York 2009.

Kotnik, V., Neposredni televizijski prenos in TV gledalec: 1. del, Monitor ISH 3 (1-2), 2001, str. 85-133.

Sandvoss, C., A game of Two halves; football, television and globalization, London, New York 2003.

Vidmar Horvat, K., Realizem na televiziji, v: Gledanje na daljavo: recepcija televizije na daljavo (ur. Zajc, M.), Ljubljana 1993, str. 205-211.

Whannel, G., Fields in vision: television sport and cultural transformation, London 1992.

\section{Elektronska vira}

http://www.youtube.com/watch?v=dBZtHAVvslQ, Youtube [16. 2. 2012].

http://www.youtube.com/watch?v=Zs2n27JBMSs\&feature=related, Youtube [16. 2.

2012]. 


\section{Mateja Veble}

\section{Television sport}

Keywords: television, sport, mediatization of sport, football, broadcasting, commentary

Today, it is difficult to imagine some sports without television and/or live broadcasting. Television has a decisive influence on our perception and understanding of sport. From the 1940's, the popularity of sport has grown in proportion with the popularity of television. Not only has their expansion and popularity increased, but both have turned so to speak into a virtual theatre. The attempt of television to place sport in entertainment section of their programming was rewarded with a record number of viewers, however, sport paid a heavy price. Today, "raw" sport does not satisfy its viewers, because they expect it to be presented as any other commodity. Since the events do not always speak for themselves, instructions and narrative are necessary to create the sense of drama for the viewer. The expectations and the experience of sport have changed as well as with the viewing patterns. Television can turn sporting events into pure action by adding episodes and information, intended to enrich the viewing experience at home. Televised sport gained freshness and appeal which cannot be denied, whereas sporting events did not have anything strong enough to oppose this development. There are various forms of televised sports; however, almost every viewer is best acquainted with sport broadcasts. Broadcasts are never only an edit of the competition. Television gives the viewer the opportunity to see more than is usually accessible to the human eye. We can say for sure that television plays the decisive role in how we see and understand sport. 